\title{
O Pensamento Econômico de Juan de Mariana
}

\author{
Alejandro Antonio Chafuen*
}

\begin{abstract}
Resumo: $\mathrm{O}$ autor sustenta neste artigo que o período da escolástica tardia, ou pósescolástica, produziu contribuições importantíssimas para a análise das questões sociais, especialmente na Economia, na Política e no Direito. Destaca Juan de Mariana como uma das figuras mais importantes desse período, cujo legado no campo das teorias sobre a inflação e outros assuntos teóricos é extremamente atual.

Palavras-Chave: Juan de Mariana, Escolástica Tardia, Alteração do Valor da Moeda, Análise Monetária.
\end{abstract}

\section{The Economic Thought of Juan de Mariana}

\begin{abstract}
The author argues that the period of late scholasticism or post-scholastic produced very important contributions to the analysis of social issues, especially in Economics, Politics and Law. He also highlights Juan de Mariana as one of the most important figures of this period whose legacy in the field of inflation and other theoretical matters is extremely modern.
\end{abstract}

Keywords: Juan de Mariana, Late Scholastics, Money Devaluation, Monetary Analysis.

Classificação JEL: B11, B31

\footnotetext{
* Alejandro Antonio Chafuen é presidente da Atlas Economic Research Foundation. Cursou a graduação em Economia na Pontificia Universidad Católica Argentina (UCA), em Buenos Aires, na Argentina, e o PhD em Economia no Grove City College, na Pennsylvania, nos EUA. É pesquisador do Acton Institute for the Study of Religion and Liberty, associado da Mont Pelerin Society e da Philadelphia Society, membro associado da John Templeton Foundation, membro do Conselho Acadêmico do Centro Interdisciplinar de Ética e Economia Personalista (CIEEP) e membro do Conselho Editorial de MISES: Revista Interdisciplinar de Filosofia, Direito e Economia. Foi agraciado com o doutorado honoris causa em Economia da Universidad Francisco Marroquín na Guatemala, com o Nassau Institute Freedom Prize, com o Global Leadership Award do Leadership Institute e com o Walter Judd Freedom Award do Fund for American Studies. Escreve uma coluna semanal na revista Forbes norte-americana. É autor de inúmeros artigos científicos publicados em diferentes revistas acadêmicas e do livro Faith and Liberty: The Economic Thought of the Late Scholastics (Lexington Books, 2003), traduzido, atualmente, para o espanhol, italiano, polonês e tcheco.

E-mail: Alex.Chafuen@AtlasNetwork.org
} 
O historiador inglês Lorde Acton (18341902) afirmou que:

A maior parte das ideias políticas de John Milton (1608-1674), John Locke (1632-1704) e Jean-Jacques Rousseau (1712-1778) podem ser encontradas nos ponderosos jesuítas latinos, súditos da coroa espanhola: em Leonardus Lessius (1554-1623), Luís de Molina (1535-1600), Juan de Mariana (15361624), Francisco Suárez (1548-1617) ${ }^{1}$.

O período da escolástica tardia (de 1300 a 1600, aproximadamente) gerou algumas das mais detalhadas análises morais das questões sociais já concebidas por autores cristãos. Os teólogos morais, em especial os que trabalhavam na Escola de Salamanca, e os que estavam nos arredores, na Espanha, apresentaram ideias penetrantes em Economia, em Política e noutras questões sociais. Acima de todos os demais jesuítas estava a figura de Juan de Mariana.

Padre Mariana foi uma das pessoas mais extraordinárias de sua época ${ }^{2}$. Alcançou fama com o tratado político De Rege et Regis Institutione [Sobre o Rei e a Instituição Real] ${ }^{3}$, lançado em 1599, e prestígio acadêmico por sua Historiae de rebus Hispaniae [História da Espanha] $]^{4}$, de 1592. O historiador inglês John Neville Figgis (1866-1919) escreveu a respeito do livro de Mariana sobre a monarquia: "O curso do argumento é excepcionalmente instrutivo, e grande parte poderia ter sido escrita por

${ }^{1}$ ACTON, John Dalberg. Essays in the History of Liberty: Selected Writings of Lord Acton. Liberty Fund: Indianapolis, 1985. p. 71.

${ }^{2}$ Para uma excelente biografia do jesuíta espanhol, ver: TALLMADGE, G. Kasten Juan de Mariana. In: SMITH, S.J., Gerard (Ed.). Jesuit Thinkers of the Renaissance. Milwaukee: Marquette University, 1939. p. 157-92.

${ }^{3}$ JUAN DE MARIANA. The King and the Education of the King. Trad. George Albert Moore. Chevy Chase, Maryland: Country Dollar Press, 1948. A introdução de George Albert Moore (1893-1971) é uma magnífica análise da vida de Mariana (p. 1-93).

${ }^{4}$ JUAN DE MARIANA. History of Spain. Trad. Cap. John Stevens. London: Richard Sare, Francis Saunders and Thomas Bennett, 1699.
Locke"5.Seu tratado DeMonetaeMutatione[Sobre a Alteração da Moeda], lançado originalmente em latim no ano de 1609 e publicado pela primeira vez em língua portuguesa na presente edição do periódico acadêmico MISES: Revista Interdisciplinar de Filosofia, Direito e Economia 6 , também deveria lhe ter granjeado a fama de um dos mais profundos pensadores econômicos de seu tempo.

Ao realizar meus estudos em escolástica tardia para o livro Faith and Liberty: The Economic Thought of the Late Scholastics ${ }^{7}$ [Fé e Liberdade: O Pensamento Econômico da Escolástica Tardia], tive o privilégio de pesquisar e viver na região em que Juan de Mariana passou a maior parte da vida - a província de Toledo, no centro de Castela. Ao caminhar pelas mesmas ruas de pedras arredondadas, cruzar os prados onde aldeias graciosas ainda pontilham a paisagem como na época de Mariana, não deixamos de notar a confluência das culturas judaica, muçulmana e cristã. Ao ler a História da Espanha de Mariana entramos no centro desse rico amálgama cultural. Estudando a obra sobre a instituição real, vemo-nos no interior de palácios, nas controvérsias da corte e nos dilemas de autoridade típicos daqueles dias. Aos vinte e três anos, antes de ser

${ }^{5}$ FIGGIS, John Neville. The Divine Right of Kings (1896). Ed. Peter Smith; Introd. G. R. Elton. Gloucester: Peter Smith Pub. Inc., 1970. p. 219-20. Na mesma passagem dessa obra o autor afirma: "Há de se notar que, embora diga no capitulo 2 que a monarquia é a melhor forma de governo, Mariana ainda assim cerca seu rei de todo tipo de limitação, de modo que ele realmente deixe a soberania com o povo [...]".

${ }^{6}$ Composta pelos capítulos I a VIII a primeira metade da obra está publicado na presente edição como: JUAN DE MARIANA. Sobre a Alteração da Moeda - Parte I. Trad. e notas Luiz Astorga. MISES: Revista Internacional de Filosofia, Direito e Economia, Volume II, Número 1 (Jan.-Jun. 2014): 163-181. A segunda parte da tradução brasileira do tratado, composta pelos capítulos IX a XIII, será publicada na próxima edição (Volume II, Número 2) de MISES: Revista Interdisciplinar de Filosofia, Direito e Economia. (N. do T.)

${ }^{7}$ CHAFUEN, Alejandro A. Faith and Liberty: The Economic Thought of the Late Scholastics. Foreword by James V. Schall, SJ. Lanham: Lexington Books, 2ª ed., 2003. 
ordenado, Juan de Mariana foi enviado para lecionar Filosofia e Teologia no Colégio Romano, na ocasião, uma das universidades de maior prestígio. Foi aí que Mariana teve como aluno Roberto Belarmino (1542-1621). Belarmino lecionou durante onze anos, a partir de 1576, no Colégio Romano. Belarmino, que foi criado cardeal e, posteriormente, canonizado, tinha crenças políticas semelhantes às de Mariana e ambos são considerados influências dos fundadores da república norte-americana. De modo geral, os jesuítas eram vistos como a influência da mudança nos séculos XVII e XVIII que afastava a teoria e prática do despotismo por direito divino e caminhava para a reabilitação das noções medievais de direitos e deveres naturais, constitucionalismo e soberania popular'.

Aos trinta e três anos Juan de Mariana foi chamado a lecionar na Universidade de Paris, na época, a instituição de ensino mais influente. Problemas de saúde fizeram com que retornasse à Espanha passados apenas quatro anos. Foi em Paris que escreveu sua Historiae de rebus Hispaniae e o tratado sobre a monarquia. A obra sobre a monarquia, requisitada por Filipe II (15271598) e dedicada a Filipe III (1578-1621), ganhou notoriedade após o assassinato de Henrique IV (1553-1610). Mariana, ao defender que o poder real derivava do povo, oferecera a justificativa para o tiranicídio a mando do povo. Em determinados círculos, Mariana tornou-se uma figura nada popular, especialmente na França, embora não surpreenda que o assassino de Henrique IV nunca tenha ouvido falar dele. O padre Jaime Luciano Balmes y Urpiá (1810-1848) questiona:

\footnotetext{
${ }^{8}$ Lorde Acton descreveu Belarmino como "o mais famoso controversista do século XVI" " "um dos mestres do catolicismo revolucionário e precursor de Algernon Sidney (1623-1683)". ACTON, John Dalberg. Lectures on Modern History. London: Macmillan and Co., 1906. p. 169.

${ }^{9}$ Sobre a temática, ver: MILLAR, S.J., Moorhouse F. X. Scholasticism and American Political Philosophy. In: ZYBURA, John S. (Ed.). Present-Day Thinkers and the New Scholasticism. St. Louis: Herder, 1927. p. 301-41.
}

Não é, portanto, digno de nota que o famoso livro [De Rege] [...] que foi queimado em Paris pelas mãos do executor público, fora publicado onze anos antes, na Espanha, sem o menor obstáculo à publicação, fosse da parte da autoridade eclesiástica ou civil? ${ }^{10}$

Juan de Mariana ingressou mais ainda na controvérsia com a publicação de um ataque ao aviltamento da moeda e ao acusar de fraude os funcionários do fisco espanhol ${ }^{11}$. Sua última década de vida foi mais calma; restringiu-se a lidar academicamente das Escrituras. Mariana faleceu em Toledo, no dia 17 de fevereiro de 1624, e Talavera de la Reina, seu local de nascimento, o homenageou com um monumento em 1888.

O tratado de Juan de Mariana sobre a alteração da moeda permite ao leitor vislumbrar o conhecimento de História e Ciência Política que esse escolástico possuía, e aborda o tema com uma profundidade econômica que não encontrei em nenhuma outra obra anterior de Economia Política.

Dada a especialização atual da academia, muitos leitores podem, à primeira vista, ficar confusos por que motivo um teólogo moral escreveria um tratado sobre a moeda. Os pensadores escolásticos eram homens de um espectro de conhecimento surpreendente. Para a maior parte desses estudiosos, a análise moral era a primeira preocupação. No entanto, como bons teólogos morais, compreendiam que, para realizar uma boa análise moral, precisavam de uma compreensão prática da questão à disposição. Se alguém quisesse entender o preço justo e a equidade nas trocas de mercado, deveria, primeiramente, compreender a teoria dos preços e como o mercado opera. No caso de Mariana, a questão com que se deparou foi a política monetária e os efeitos sobre o bem comum do

10 BALMEZ [sic], J. European Civilisation: Protestantism and Catholicity Compared. London: Burns and Lambert, 3a ed., 1861. p. 296.

${ }^{11}$ MARTIN, M. B., Mariana, Juan de. New Catholic Encyclopedia. San Francisco: McGraw-Hill, 1976. Vol. 9, p. 213. 
reino. Escreveu esse tratado oferecendo suas percepções ao rei, aconselhando o soberano como proteger o bem-estar econômico da nação. Desse modo, não é somente uma análise moral da política monetária, mas também um brilhante tratado econômico.

Juan de Mariana é ainda mais conhecido pelas contribuições históricas. Foi um escritor magnífico. O padre John Laures S.J. escreveu que a obra História da Espanha de Mariana "ainda é considerado uma obra-prima do estilo clássico espanhol"12. E seu trabalho histórico não deixa de ser notado pelos pais fundadores dos Estados Unidos, visto que Thomas Jefferson (1743-1826) recomendou o livro sobre história da Espanha de Mariana a James Madison $(1751-1836)^{13}$.

Também como foi observado por Edwin R. A. Seligman (1831-1939) na introdução ao estudo sobre as teorias monetárias de Mariana de John Laures: "A fama de Mariana, ou melhor, sua notoriedade, como defensor da monarquia, fez com que todo o mundo moderno negligenciasse seus feitos substanciais no campo da Economia"14. Entretanto, seus atributos como economista não passaram totalmente desapercebidos por Oscar Jàszi (1875-1957) e John Donald Lewis (1905-1988), que na obra de Ciência Política Against the Tyrant [Contra o Tirano], tiveram a sabedoria de afirmar que Mariana era um "economista político arguto"15.

No mundo de língua espanhola, Mariana é só um pouco mais conhecido como economista político. Juan José Guaresti (1907-

${ }^{12}$ LAURES, S.J., John. The Political Economy of Juan De Mariana John. Foreword by Edwin R. A. Seligman. New York: Fordhan University Press, 1928. p. 3.

${ }^{13}$ PETERSON, Merrill D. (Ed.). Jefferson Writings: Autobiography, Notes on the State of Virginia, Public and Private Papers, Addresses, Letters. New York: Library of America, 1984. p. 820-25.

${ }^{14}$ SELIGMAN, Edwin R. A. Foreword. In: LAURES, S.J. The Political Economy of Juan De Mariana John. p. v.

${ }^{15}$ JÀSZI, Oscar \& LEWIS, John D. Against the Tyrant: The Tradition and Theory of Tyrannicide. Glencoe: The Free Press, 1957. p. 68. O manuscrito do livro de Oscar Jàszi e John Lewis foi lido por cientistas sociais do calibre de Frederick Artz, Michael Polanyi e von Neumann.
1974), um célebre professor argentino da década 1960, dedica uma extensa seção de seu livro-texto ${ }^{16}$ a Mariana. Em "Biography of Juan de Mariana: The Influence of the Spanish Scholastics (1536-1624)" [Bibliografia de Juan de Mariana: A Influência da Escolástica Espanhola], o economista espanhol Jesús Huerta de Soto finalmente começa a dar o devido crédito a esse jesuíta ${ }^{17}$. Oferece uma nova visão sobre a influência de Mariana na pré-história da economia "austríaca". A nova e próspera escola de personalismo econômico certamente o enumeraria como um dos precursores.

Mariana envolveu-se em mais problemas quando criticou um instrumento de tirania do que quando criticou seus aspectos gerais. George Albert Moore (1893-1971), na excelente introdução a De Rege et Regis Institutione de Mariana explica os riscos desse tipo de assunto:

O De Monetae Mutatione era, igualmente, um assunto perigoso, pois, como ressalta Bodin na Réponse aux paradoxes de M. de Malestroit (1568), a questão da depreciação da moeda era a fraude típica de reis e príncipes $^{18}$. Esse tratado fez com que Mariana ficasse preso de quatro meses a um ano, perdesse seus escritos, que parece nunca mais foram devolvidos, e sofresse uma ameaça de ação urgente da temida Inquisição, e tudo isso em idade avançada ${ }^{19}$.

16 GUARESTI, Juan José. Economía Polítca: Las Doctrinas Económicas. Buenos Aires: Kraft, 1963.

17 DE SOTO, Jesus Huerta. Biography of Juan de Mariana: The Influence of the Spanish Scholastics (15361624). In: https://mises.org/page/1458/Biographyof-Juan-de-Mariana-The-Influence-of-the-SpanishScholastics-15361624

18 Henry Hallam (1777-1859), o grande historiador da Idade Média classificou a prática comum da depreciação monetária como "um vasto plano de pilhagem" e "combinava-se com a fraude e o roubo". HALLAM, Henry. View of the State of Europe during the Middle Ages. $4^{\text {th }}$ ed, London: Alex Murray and Son, 1868. p. 110-11.

${ }^{19}$ MOORE, George Albert. Introduction. In: JUAN DE MARIANA. The King and the Education of the King. p. 79-80. 
Eloi Castelot (1844-1919), ao escrever sobre Juan de Mariana no Palgrave's Dictionary of Political Economy [Dicionário Palgrave de Economia Política], também menciona que esse escrito fez com que ele ficasse "confinado por um ano em um convento em Madri"20.

\section{As Contribuições de Juan de Mariana para a Análise MONETÁRIA}

Juan de Mariana ressaltou que "se o valor legal do dinheiro não decresce, certamente as mercadorias todas subirão de preço, na exata medida em que do dinheiro se subtraiu qualidade ou peso" ${ }^{\prime 21}$. Observou que a desvalorização da moeda produzirá os mesmos resultados ${ }^{22}$.

Juan de Mariana comparou a transferência de riqueza pela desvalorização da moeda à ação de alguém que vai aos celeiros privados e rouba uma parcela dos grãos ali estocados:

Não está sob o arbítrio do rei lançar-se sobre os bens dos súditos e subtraí-los como queira dos seus donos legítimos. Agora vejamos: acaso seria lícito ao príncipe invadir os celeiros um a um, tomar para si a metade do trigo armazenado e compensar este prejuízo dando ao dono o direito de vender o que restou pelo preço do volume original inteiro? Não creio haver homem de juízo tão desvairado que escuse tal ação. Ora, mas foi isto o que se fez com a antiga moeda de cobre ${ }^{23}$.

Juan de Mariana observou que quando o rei cunhava uma nova moeda, subtraía da

${ }^{20}$ CASTELOT, E. Juan de Mariana, S.J. In: Palgrave's Dictionary of Political Economy. London: Macmillan, 1926. Vol. II, p. 692.

${ }^{21}$ JUAN DE MARIANA. Tratado sobre a Alteração da Moeda. Cap. IV. Mariana acrescentou que "Acaso são sonhos isto que digo, coisas não provadas com exemplos da memória dos antigos?" (Cap. X).

${ }^{22}$ Idem. Ibidem., Cap. X.

${ }^{23}$ Idem. Ibidem., Cap. X. moeda dois terços de seu valor, deixando aos súditos, um terço ${ }^{24}$. Ao prever que "todo o povo voltará à pobreza e haverá tumultos", Mariana empregou as seguintes expressões "Um roubo infame! Um peculato torpíssimo!"25 a tal manipulação da oferta de moeda.

Juan de Mariana atribuía imensa importância à moeda forte. A moeda, juntamente com pesos e medidas, é a base do comércio e dos contratos. Por esse motivo, disse:

Os fundamentos do comércio, aquilo no qual se apoia toda a estrutura mercantil, são certamente os pesos, as medidas e o dinheiro. Muitas coisas se vendem por peso e medida, mas todas por dinheiro. No que tange a isto, assim como estão todos convencidos de que uma construção deve ter fundamentos imóveis e intactos, o mesmo vale para pesos, medidas e dinheiro ${ }^{26}$.

Ao citar o livro de Levítico 27, 25, Juan de Mariana estipulou que a pureza e o justo preço da moeda deveriam estar guardados no templo ${ }^{27}$. O siclo guardado no templo deveria ser o padrão de valor. Mariana, também, citou o De Regimine Principum [Do Governo dos Príncipes] Santo Tomás de Aquino (1225-1274) e aconselhou ao príncipe a não alterar o câmbio ao bel prazer $^{28}$, pois,:

\footnotetext{
${ }^{24}$ Idem. Ibidem., Cap. X.

25 "Infame latrocinio". Idem. Ibidem., Cap. X.

${ }^{26}$ Idem. Ibidem., Cap. V.

27 "Omnis aestimatis siclo sanctuari ponderatur". Idem. Ibidem., Cap. V.
}

${ }^{28}$ O texto De Regimine Principum [Do Reino ou do Governo dos Príncipes] é de autoria parcial de Santo Tomás de Aquino, no entanto, a passagem citada (Livro II, Cap. 14) por Juan Mariana pertence a parte escrita por Ptolomeu de Lucca (1236-1326). Em português encontramos a obra nas seguintes versões: TOMÁS DE AQUINO, São. Do Reino ou Do Governo dos Príncipes ao Rei de Chipre. Trad. Carlos A. R. do Nascimento. Petrópolis: Vozes, 1997. Uma edição mais recente, apenas com o livro I está disponível na respectiva edição: TOMÁS DE AQUINO, São. Do Governo dos Príncipes ao Rei de Cipro. Trad. Arlindo Veiga dos Santos. São Paulo: EDIPRO, 2013. (N. do T.) 
"Além de outros incômodos, surgiu a necessidade de comparar as medidas recentes com as antigas, as nossas com as estrangeiras; uma nova confusão. Desta feita, parecem pouco eruditos aqueles com quem está o governo das coisas, pois não atinam com os males e perturbações que, em nossa gente e entre os estrangeiros, comumente emanam desta fonte. Era fácil perceber que a desvalorização da moeda seria algo rentável ao monarca, e consta que muitas vezes os antigos foram levados à fraude por esse anseio. Mas logo puderam dar-se conta dos infortúnios nos quais em seguida precipitaram-se, uma vez feita esta alteração".

Para remediar tais problemas, foram frequentemente necessários novos e maiores males, que em seu lugar serão explicados ${ }^{29}$.

Tentar resolver problemas econômicos alterando a moeda, segundo Juan de Mariana, era como dar bebida alcólica para um doente. No primeiro momento, reaviva, mas depois agrava e piora a doença ${ }^{30}$. Mariana explicou que o rei poderia usar moedas de qualidade inferior para pagar suas dívidas e diminuir alguns problemas. Acrescenta também que, no curto prazo, o aumento da oferta de moeda causaria um aumento na produção. Aumentaria a demanda por bens e "todos gastarão antes a moeda de cobre e reterão a de prata"31. Ao observar que a maioria dos tiranos que aviltam a moeda adotaram a moeda de cobre (moneda de vellón) sem nada de prata ou de ouro, Mariana formula o que, posteriormente, vem a ser chamado de "Lei de Gresham". Quando a moeda de cobre é abundante e sobrevalorizada, expulsa a cunhagem de prata (que é artificialmente subvalorizada $)^{32}$.

${ }^{29}$ JUAN DE MARIANA. Tratado sobre a Alteração da Moeda. Cap. V. Os "novos e maiores males" foram o controle de preços. Mariana disse que seria um erro impô-los. Ao afirmar que "estes se recusarão a vender", observou que tal remédio não curaria, mas pioraria a situação (Ver: Idem. Ibidem., Cap. X).

${ }^{30}$ Idem. Ibidem., Cap. IX.

${ }^{31}$ Idem. Ibidem., Cap. IX.

32 "Todos gastarão antes a moeda de cobre e reterão a de prata". Idem. Ibidem., Cap. IX.
No capítulo $X$ do tratado da moeda, Juan de Mariana listou os sérios incovenientes decorrentes de um processo de aumento artificial na oferta de moeda. Começou por provar que essa ação violava as leis da Espanha. Segundo ele, é aceitável utilizar a moeda de cobre apenas para transações comerciais de pequena monta. O dinheiro foi "foi inventado para facilitar o comércio", que é sua função principal. A melhor moeda é aquela que cumpre melhor sua função. Não é necessário ter somente ouro e prata ou proibir o uso de moedas de cobre, disse, mas "seria muito mais nocivo pecar pelo outro extremo e inundar a nação com moedas de cobre" ${ }^{\prime 3}$.

Além disso, Juan de Mariana afirmou que a desvalorização da moeda contradiz tanto a razão como a lei natural. Uma vez que viola os direitos de propriedade, equivale a pilhagem. Sob essa luz, também é injusto oferecer moeda desvalorizada em pagamento das dívidas contraídas em moeda forte ${ }^{34}$. Mariana observou que isso não foi feito com outros bens, pois o rei não os possuía. Concluiu por dizer que onde quer que o rei tenha poder de administrar os bens, é razoável esperarmos por fraude.

Para Mariana, um dos efeitos mais negativos da desvalorização da moeda ocorre na arena política. $\mathrm{O}$ rei sofrerá caso sua renda decresça. As atividades comerciais diminuirão, e a pobreza do povo levará à pobreza do reino ${ }^{35}$. As pessoas começarão a odiar o príncipe $^{36}$. Apesar da verdade dessas afirmações, Mariana ressaltou que:

Cega-nos a cupidez, premem-nos as necessidades do erário, e esquecemo-nos do passado; assim volta a surgir este conjunto de males. Muito me admira que entre os que governam haja gente que ignore estes fatos - pois, se os conhecem, quão temerários são em desejar com ciência e aviso precipitar-se em tal abismo de perigos! ${ }^{17}$

\footnotetext{
${ }^{33}$ Idem. Ibidem., Cap. IX.

${ }^{34}$ Idem. Ibidem., Cap. X.

${ }^{35}$ Idem. Ibidem., Cap. X.

${ }^{36}$ Idem. Ibidem., Cap. X.

${ }^{37}$ Idem. Ibidem., Cap. $\mathbf{X}$
} 
Definiu a desvalorização da moeda como uma espécie de imposto e comentou que tais tributações "assim teremos o povo premido sob um novo e pesadíssimo tributo" ${ }^{38}$. Com base nos muitos argumentos, concluiu:

A meu ver, toda alteração de moeda é repleta de perigos, e nunca convém cunhála de maneira ilegítima, de modo que, por decreto, se dê mais em troca de algo que vale menos segundo estimação comum ${ }^{39}$.

Algumas frases adiante, Mariana aconselha ser melhor deixar as coisas como estão, sem alterações na moeda, porque a única pessoa que pode lucrar com o aviltamento da moeda é o príncipe "os quais [benefícios] nem sempre são algo por conquistar-se, especialmente por meios como esta adulteração" ${ }^{\prime 4}$.

Mariana condenou a desvalorização da moeda, chamando-a de prática "bárbara". Aqueles que propõem tal coisa, escreveu, podem ser propriamente descritos como a praga da república ${ }^{41}$.

Poderá, por acaso, continuar exercendo esta função [de instrumento geral de câmbio] se começarmos a tomar a liberdade de rebaixar a pureza do ouro ou da prata em dois porcento ou mais? O comércio exterior, em breve, será impossível se os mercadores nacionais não consentirem em sofrer uma perda equivalente a depreciação da moeda; introduzir-se-á no comércio nacional a desconfiança, seguida, necessariamente, da paralisação de obras, escassez, encarecimento de produtos, miséria, confusão, desordem. O governo, é verdade, poderá obrigar-me a aceitar em troca de meus artigos a moeda nova; mas não poderia, de minha parte, aumentar o preço dos mesmos até cobrir o défict que a arbitrária alteração dos metais poderá ocasionar? Serão inúteis, graças ao desejo natural de conservar os próprios interesses, todos os esforços do

\footnotetext{
${ }^{38}$ Idem. Ibidem., Cap. X

${ }^{39}$ Idem. Ibidem., Cap. XII.

${ }^{40}$ Idem. Ibidem., Cap. XII.

${ }^{41}$ PI Y MARGALL, Francisco. Discurso Preliminar. In: Biblioteca de Autores Españoles: Desde la formación del lenguaje hasta nuestros días. Madri: M. Rivadeneyra, 1864. Vol. 30, Tomo I, p. xxxvi.
}

rei para evitar a evolução que será imposta a mim e a todos? Nascem tão espontaneamente os tristes resultados do caráter dessa mesma disposição, que não é necessário mais consultar a razão para prevê-los; todavia, agora não é apenas a razão, é a experiência, e uma experiência bastante funesta, que os escreve com lágrimas e sangue ${ }^{42}$.

Mariana compreendeu que a desvalorização da moeda ameaçava toda a ordem econômica do reino. Direitos de propriedade, a capacidade de intercambiar bens e serviços, salários justos - todas essas coisas requeriam uma moeda estável. Nenhum indivíduo tem o direito de esperar que as leis que regem os direitos de propriedade, ou seus direitos como consumidor ou produtor, sempre admitirão a mesma forma. Entretanto, a manutenção de uma ordem monetária livre indica que os contratos espontanemente acordados em moeda, como tais, encerrem a garantia da sociedade de que a referência monetária, segundo os termos estabelecidos no momento da consecução, não seja deliberadamente adulterada por ninguém, nem mesmo pelo governo.

Um otimismo imediatista, ocasionado pela diminuição da desvalorização da moeda durante a última década do século $X X$, pode ter obnubilado a atualidade dessa primeira edição em português, contudo, os governos em todos os continentes ainda consideram o controle monetário como uma ferramenta essencial usada, na maioria das vezes, para corromper, em vez de proteger, os cidadãos. No atual momento em que a Igreja católica tem um pontífice jesuíta, os escritos econômicos de Mariana podem, novamente, ser influentes e inspirar uma tendência saudável para que foquemos nos aspectos morais da Economia, especialmente na arena monetária.cos

\footnotetext{
${ }^{42}$ Idem. Ibidem., p. xxxvi.
} 